\title{
Prevalence of Burnout Syndrome in Medicine Students from a University Institution of Cartagena
}

\author{
Ingrid González Arteta* \\ Dentist, Specialist in Quality Assurance Systems and Audit of health services, Epidemiology, Master in Technological Resources \\ applied to Education, Columbia
}

*Corresponding author: Ingrid González Arteta, Dentist, Specialist in Quality Assurance Systems and Audit of health services, Epidemiology, Master in Technological Resources applied to Education, Columbia

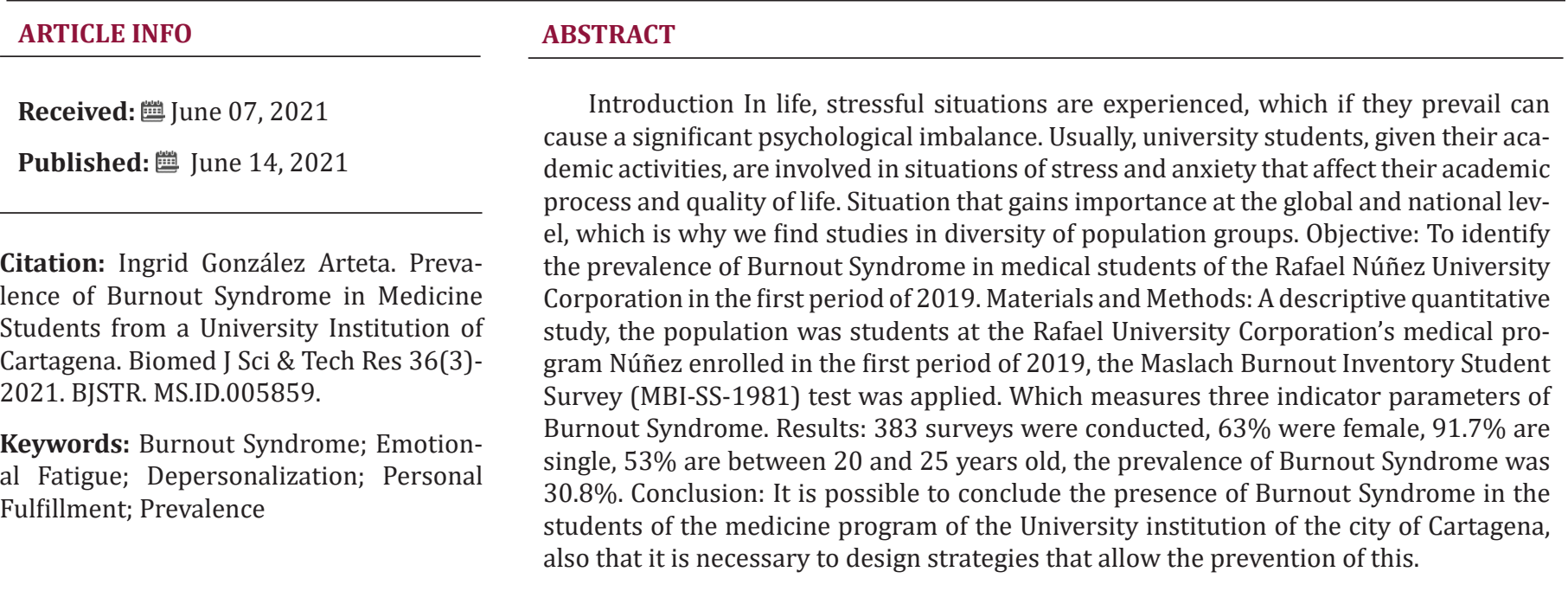

\section{Introduction}

The Burnout Syndrome (SB) is the result of the constant stress of people towards the work or student activity that they exercise, producing states of fatigue, mental fatigue, low self-esteem and changes in their behavior that can progressively lead to states of disinterest towards what it does, causing even the development of deep depressions [1]. This important impact on the population, aroused research interest in studying the prevalence of Burnout Syndrome in medical students at a university institution in Cartagena - Colombia. Medicine is a highly demanding discipline, students are exposed to constant demands, which as they advance, they become stronger, which if they are not given proper management, can lead them to develop a psychological imbalance, reaching the Syndrome of Burnout, and also to the presentation of pathophysiological processes [2]. This Syndrome may then be one of the main causal agents of the low academic performance of some students due to the lack of interest, and even of the repetition and

multi appearance that usually occurs in this area; which would lead to confirming its presence, serving as an element of analysis to propose strategies for its early detection, thus the necessary management measures could be implemented for students who already suffer from it, contributing to better academic performance and student progress of students in the medical program.

Several studies have been carried out on this subject, such as the one carried out by Felipe Serrano et al., The objective of which was to determine the prevalence of BS in medical students from six colleges in Colombia, a descriptive, cross-sectional, metacentric observational study, surveying 180 students of six Colombian medical schools using convenience sampling. Positive or negative BS was defined according to the Maslach Burnout Inventory-Student Survey [MBI-SS] test, in addition to measuring other academic and socio-economic variables, the median age was 20 years [interquartile range: 19-22 years], 52\% (94) were 
men. $10 \%$ (18) had positive BS, with ranges of $0-23 \%$ depending on the location of the respondent, the frequency increasing as the year of study increased, except for the first and sixth years. In their three criteria, 36.8\% [66] had emotional exhaustion; $37.2 \%$ [67], cynicism and $25.6 \%$ [46] low academic self-efficacy, finding a low prevalence of BS among medical students in relation to other studies, recommending starting programs aimed at preventing and improving mental health of future health professionals [3]. Mayron D. Nakandakari and collaborators, carried out the Burnout Syndrome study in medical students of Peruvian scientific societies, a multicenter study, its objective was to identify the frequency of Burnout Syndrome [SB] in medical students, it was an observational study , descriptive and transversal. The population studied were all human medicine students belonging to 9 scientific societies from different departments of Peru and affiliated with the Peruvian Student Medical Scientific Society [SOCIMEP]. They applied a survey with biographical data and the Maslach Burnout Inventory. 158 human medicine students were surveyed, $24.1 \%$ had a severe level of emotional exhaustion, $45.6 \%$ a severe level of depersonalization, $25.3 \%$ a low level of personal fulfillment and 57.6\% had SB, $60.8 \%$ of the students were doing some research work and $49.4 \%$ held a position in their scientific society. concluding that there was a important frequency of SB in medical students belonging to the scientific societies studied [4].

Africa Martos and collaborators carried out the Burnout and engagement study in health science students, analyzed their level, as well as their perceived health. Likewise, the importance of Emotional Intelligence in preventing the development of burnout, the sample was 63 students who were studying higher degrees in health sciences, who were administered the version for students of the Maslach Burnout Inventory and the Scale of Well-being in the Academic Context. They found that there are no statistically significant differences in Burnout and Engagement between university nursing students and young people who attend professional training as Auxiliary Nursing Care Technician. At the same time, dedication to studies was shown to be related to perceived health. Finally, the existence of significant differences between nursing and ED students was found in the Intrapersonal factor. So it was the TCAE students who showed higher intrapersonal emotional intelligence [5]. Luis Alfredo Núnez-Joseli, and collaborators, they carried out the study Prevalence of Burnout Syndrome in Human Medicine Students of a Public University in Peru, whose objective was to determine the prevalence of Burnout Syndrome students and its dimensions, as well as its factors. associates in medical students of the Faculty of Human Medicine, carried out a crosssectional study using two anonymous self-administered surveys, one related to sociodemographic characteristics and the other, the Maslach Burnout Inventory scale in its version for [MBI-SS], they surveyed a total of 368 [59.5\%] students, where the mean age was 22.11, with a predominance of sex
$53 \%$ female $[\mathrm{n}=195]$. The prevalence of BS was $12 \%$ [ $n=45]$, $34.5 \%$ [ $n=127$ ] showed high levels of emotional exhaustion, $25 \%$ [ $n=92]$ high levels of depersonalization, and 28.8\% [ $n=106]$ low levels of personal fulfillment, concluded that there was a low prevalence of BS, although it is within the trend revealed by other similar studies. The dimension of emotional exhaustion was the most prevalent, which fits within the cascade of symptoms that finally triggers BS [6]. The objective of this study was to identify the prevalence of Burnout Syndrome in medical students at a university institution in Cartagena, for which the population under study was characterized, in the demographic variables, age, sex, marital status, semester, they were determined the factors related to the development of the Burnout Syndrome, according to the values Emotional exhaustion, Depersonalization, lack of personal fulfillment in the study, applying the Maslach Burnout Inventory Student Survey questionnaire (MBI-SS-1981) [7].

\section{Materials and Methods}

A descriptive, cross-sectional study was carried out, the population were students enrolled in the first period of 2019, to the Medicine program of a university institution in Cartagena. Students from $1^{\text {st }}$ to $12^{\text {th }}$ Semester were taken, the Maslach Burnout Inventory Student Survey \{MBI-SS-1981\} test was used, validated in the Colombian academic context, by Hedrech, Caballero and Domínguez, which identifies three factors: emotional exhaustion, depersonalization and lack of personal fulfillment in 22 items $[7,8]$. A stratified probability sampling of proportional allocation was carried out, applying the formula for finite population, working with a confidence level of $95 \%$ and a margin of error of $5 \%$, giving a sample of 270 , they were placed in the platform via email, for this purpose 2 calendar months of the first academic period of 2019 were used. This study was carried out by sensitizing the population through mass emails where they were informed about the purpose of the study and the dates of application of the instrument, which was done in a self-administered way. The tabulation, systematization and analysis of the information was carried out by means of the statistical package epi info 7.2.2., For the categorical variables measured of the distribution of frequencies and prevalence's, the Shapiro-Wilk test was also applied. Age will be represented by measures of central tendency, for this study an informed consent was drawn up in accordance with the Declaration of Helsinki of 1975 in its ninth principle: "In medical research in human beings capable of giving informed consent, each participant potential must receive adequate information about the objectives, methods, sources of funding, possible conflicts of interest, institutional affiliations of the researcher, calculated benefits, foreseeable risks and discomforts derived from the experiment, post-study stipulations and all other pertinent aspects of the investigation "[World Medical Association, 1964], as well as resolution 8430 of 1993 of the Ministry of Health, in its article 11 specifies that it categorizes research without risk. 


\section{Results}

The present study was carried out with students enrolled in the medicine program in the 1st period of 2019, with a universe of 902 students, 383 surveys were applied after accepting informed consent, of these, 10 were discarded due to poor completion and / or non-acceptance of informed consent, leaving 373, with the third semester being the one with the highest participation with $11 \%$ and the eleventh semester the lowest with $6 \%$, a prevalence of BS was found in all students of $30.8 \%$, a mean of 18 years, a median of 20 and a mode of 19 for the age with a standard deviation of 22 for the same variable, applied the Shapiro-Wilk test, the alternative hypothesis was accepted since the p found was less than $95 \%$, which is interpreted as having a high probability of BS in the studied population (Table 1). The highest percentage of respondents were female with $63 \%$ [235], the age range with the highest frequency was 20 to 25 years with 53\% [199], referring to their academic condition discriminated as, none is to say that the students take the subject for the first time, repeaters who take the subject for the second time and multirepeakers those who repeat for the third time and more, with the highest number of students being those of none with $90.3 \%$ [337], and those with the lowest frequency were multirepitents with $0.5 \%$ [2], and the marital status of the participants was also investigated, being single the most frequent with $91.7 \%$ [342], and the one with the least frequency being married with $2.4 \%$ [9] (Table 2).

Table 1.

\begin{tabular}{|c|c|c|c|c|c|c|c|c|c|c|c|c|c|}
\hline Semester & I & II & III & IV & V & VI & VII & VIII & IX & $\mathbf{x}$ & XI & XII & NULAS \\
\hline Frequency & 39 & 34 & 43 & 38 & 44 & 36 & 24 & 28 & 21 & 21 & 22 & 23 & 10 \\
\hline Percentage & 10 & 9 & 11 & 10 & 11 & 9 & 6 & 7 & 5 & 5 & 6 & 6 & 3 \\
\hline
\end{tabular}

Table 2.

\begin{tabular}{|c|c|c|c|c|c|}
\hline Gender & $\begin{array}{c}\text { Freq } \\
\end{array}$ & $\%$ & Academic Condition & $\begin{array}{c}\text { Freq } \\
.\end{array}$ & $\%$ \\
\hline Male & 138 & 37 & None & 337 & 90,3 \\
\hline Feminine & 235 & 63 & Repeating & 34 & 9,1 \\
\hline Age & Frec. & $\%$ & Multirepitents & 2 & 0,5 \\
\hline 15 a 19 & 150 & 40 & Civil status & Freq & $\%$ \\
\hline 20 a 25 & 199 & 53 & Single & 342 & 91,7 \\
\hline 26 y Mas & 24 & 6 & Married & 9 & 2,4 \\
\hline & & & U. Libre & 22 & U. Free \\
\hline
\end{tabular}

Applying the Maslach Burnout Inventory student instrument, it was found that the students show high levels in the three aspects that are considered related to the Burnout Syndrome, these values were 41 [VR 27 to 54 high], also for the depersonalization aspect the Values obtained were 29 [VR 10 to $30 \mathrm{high}$ ], for personal fulfillment values of 45 [VR 40 to 56 high] were obtained, in relation to gender it was found for the three aspects, emotional fatigue, depersonalization and personal fulfillment in the masculine gender values of 20 being for average emotional fatigue, [RV19 to 26 medium], for depersonalization [RV 10 to $30 \mathrm{high}$ ] and for personal fulfillment [RV 0 to $33 \mathrm{low}$ ]. For the female gender, the value obtained in emotional fatigue was 34 [VR 27 to 54 high], the depersonalization aspect, the value obtained was 30 [VR 10 to $30 \mathrm{high}$, regarding the aspect of personal fulfillment, values of 34 were obtained [VR 34 to 39 medium] (Table 3). Reviewing the results by semester, it was found that the third, fourth and sixth semesters were found to have the three high aspects, which shows the Syndrome. Likewise, the other semesters show two of the three high aspects, which are considered to have strong indications of suffering from SB (Table 4). Aspects of Burnout Syndrome related to age ranges and academic condition were looked at, finding that the group of students between 20 and 25 years of age showed high values for emotional fatigue and depersonalization and low for personal fulfillment, which refers to strong indications of Syndrome, being those with the lowest risk those over 26 years of age, for the academic condition, high values were obtained in the three aspects for the group of students whose condition is none, and for the group of repeaters, the aspects of emotional fatigue and depersonalization, with high values while for personal fulfillment the values that were obtained were in the middle term taking into account the reference ones, which shows high signs of the Syndrome (Table 5). 
Table 3.

\begin{tabular}{|c|c|c|c|c|}
\hline $\begin{array}{c}\text { Appearance of Burnout } \\
\text { Syndrome }\end{array}$ & \multicolumn{2}{|c|}{ Obtained Value } & \multicolumn{2}{|c|}{ Reference value } \\
\hline Emotional tiredness & \multicolumn{2}{|c|}{41} & 27 a 54 & Alto \\
\hline Depersonalization & \multicolumn{2}{|c|}{29} & 10 a 30 & Alto \\
\hline Personal fulfillment & \multicolumn{2}{|c|}{45} & 40 a 56 & Alto \\
\hline Appearance of Burnout Syndrome & Vr Ob. & \multirow{2}{*}{ Vr. Ref. } & Vr Ob. & \multirow{2}{*}{ Vr. Ref. } \\
\hline Gender & More. & & Fem. & \\
\hline Emotional tiredness & 20 & 19 a 26 Medio & 34 & 27 a 54 Alto \\
\hline Depersonalization & 20 & 10-30 Alto & 30 & 10-30 Alto9 \\
\hline Personal fulfillment & 20 & 0 a 33 Bajo & 34 & 34 a 39 Medio \\
\hline
\end{tabular}

Table 4.

\begin{tabular}{|c|c|c|c|c|c|c|c|c|c|c|c|c|}
\hline $\begin{array}{c}\text { Appearance of } \\
\text { Burnout Syndrome }\end{array}$ & Vr Ob. & Vr. Ref. & Vr Ob. & Vr. Ref. & Vr Ob. & Vr. Ref. & Vr Ob. & Vr. Ref. & Vr Ob. & Vr. Ref. & Vr Ob. & Vr. Ref. \\
\hline Semester & \multicolumn{2}{|c|}{ I } & \multicolumn{2}{|c|}{ II } & \multicolumn{2}{|c|}{ III } & \multicolumn{2}{|c|}{ IV } & \multicolumn{2}{|c|}{ v } & \multicolumn{2}{|c|}{ VI } \\
\hline Emotional tiredness & 50 & $\begin{array}{l}27 \text { a } 54 \\
\text { Alto }\end{array}$ & 44 & $\begin{array}{l}27 \text { a } 54 \\
\text { Alto }\end{array}$ & 54 & $\begin{array}{l}27 \text { a } 54 \\
\text { Alto }\end{array}$ & 49 & $\begin{array}{l}27 \text { a } 54 \\
\text { Alto }\end{array}$ & 45 & $\begin{array}{l}27 \text { a } 54 \\
\text { Alto }\end{array}$ & 37 & $\begin{array}{l}27 \text { a } 54 \\
\text { Alto }\end{array}$ \\
\hline Depersonalization & 28 & $\begin{array}{c}10-30 \\
\text { Alto }\end{array}$ & 24 & $\begin{array}{c}10-30 \\
\text { Alto }\end{array}$ & 30 & $\begin{array}{c}10-30 \\
\text { Alto }\end{array}$ & 27 & $\begin{array}{c}10-30 \\
\text { Alto }\end{array}$ & 30 & $\begin{array}{l}10-30 \\
\text { Alto }\end{array}$ & 26 & $\begin{array}{l}10-30 \\
\text { Alto }\end{array}$ \\
\hline Personal fulfillment & 31 & $\begin{array}{c}0 \text { a } 33 \\
\text { Bajo }\end{array}$ & 32 & $\begin{array}{l}0 \text { a } 33 \\
\text { Bajo }\end{array}$ & 40 & $\begin{array}{l}40-48 \\
\text { Alto }\end{array}$ & 33 & $\begin{array}{l}40-48 \\
\text { Alto }\end{array}$ & 39 & $\begin{array}{l}34-39 \\
\text { Medio }\end{array}$ & 33 & $\begin{array}{l}40-48 \\
\text { Alto }\end{array}$ \\
\hline $\begin{array}{c}\text { Appearance of } \\
\text { Burnout Syndrome }\end{array}$ & Vr Ob. & Vr. Ref. & Vr Ob. & Vr. Ref. & Vr Ob. & Vr. Ref. & Vr Ob. & Vr. Ref. & Vr Ob. & Vr. Ref. & Vr Ob. & Vr. Ref. \\
\hline Semester & \multicolumn{2}{|c|}{ VII } & \multicolumn{2}{|c|}{ VIII } & \multicolumn{2}{|c|}{ IX } & \multicolumn{2}{|c|}{$\mathbf{X}$} & \multicolumn{2}{|c|}{ XI } & \multicolumn{2}{|c|}{ XII } \\
\hline Emotional tiredness & 31 & $\begin{array}{l}19-26 \\
\text { Medio }\end{array}$ & 36 & $\begin{array}{l}27 \text { a } 54 \\
\text { Alto }\end{array}$ & 27 & $\begin{array}{l}27 \text { a } 54 \\
\text { Alto }\end{array}$ & 27 & $\begin{array}{l}27 \text { a } 54 \\
\text { Alto }\end{array}$ & 28 & $\begin{array}{l}27 \text { a } 54 \\
\text { Alto }\end{array}$ & 30 & $\begin{array}{l}27 \text { a } 54 \\
\text { Alto }\end{array}$ \\
\hline Depersonalization & 17 & $\begin{array}{l}10-30 \\
\text { Alto }\end{array}$ & 20 & $\begin{array}{l}10-30 \\
\text { Alto }\end{array}$ & 15 & $\begin{array}{l}10-30 \\
\text { Alto }\end{array}$ & 15 & $\begin{array}{l}10-30 \\
\text { Alto }\end{array}$ & 16 & $\begin{array}{l}10-30 \\
\text { Alto }\end{array}$ & 16 & $\begin{array}{c}10-30 \\
\text { Alto }\end{array}$ \\
\hline Realización Personal & 22 & $\begin{array}{l}0-33 \\
\text { Bajo }\end{array}$ & 28 & $\begin{array}{l}0-33 \\
\text { Bajo }\end{array}$ & 19 & $\begin{array}{l}0 \text { a } 33 \\
\text { Bajo }\end{array}$ & 20 & $\begin{array}{l}0 \text { a } 33 \\
\text { Bajo }\end{array}$ & 19 & $\begin{array}{l}0 \text { a } 33 \\
\text { Bajo }\end{array}$ & 22 & $\begin{array}{l}0 \text { a } 33 \\
\text { Bajo }\end{array}$ \\
\hline
\end{tabular}

Table 5.

\begin{tabular}{|c|c|c|c|c|c|c|}
\hline $\begin{array}{c}\text { Appearance of Burnout } \\
\text { Syndrome }\end{array}$ & Vr Obt. & Vr.Ref. & Vr Obt. & Vr. Ref. & Vr Obt. & Vr. Ref. \\
\hline AGE & \multicolumn{2}{|c|}{15 a 19} & \multicolumn{2}{|c|}{20 a 25} & \multicolumn{2}{|c|}{26 y Mas } \\
\hline Emotional tiredness & 21 & 19 a 26 Medio & 28 & 27 a 54 Alto & 3 & 0 a 18 Bajo \\
\hline Depersonalization & 21 & 10-30 Alto & 28 & $10-30$ Alto & 3 & 0 a 5 Bajo \\
\hline Personal fulfillment & 21 & 0 a 33 Bajo & 28 & 0 a 33 Bajo & 3 & 0 a 33 Bajo \\
\hline $\begin{array}{l}\text { Appearance of Burnout } \\
\text { Syndrome }\end{array}$ & Vr Obt. & Vr. Ref. & Vr Obt. & Vr. Ref. & Vr Obt. & Vr. Ref. \\
\hline Academic Condition & \multicolumn{2}{|c|}{ None } & \multicolumn{2}{|c|}{ Repeating } & \multicolumn{2}{|c|}{ Multirep. } \\
\hline Emotional tiredness & 48 & 27 a 54 Alto & 44 & 27 a 54 Alto & 2 & 0 a 18 Bajo \\
\hline Depersonalization & 26 & 10-30 Alto & 24 & 10-30 Alto & 3 & 0 a 5 Bajo \\
\hline Personal fulfillment & 54 & 40 a 54 Alto & 39 & 34 a 39 Medio & 3 & 0 a 33 Bajo \\
\hline
\end{tabular}

\section{Discussion}

Academic burnout comes from the presumption that students, specifically university students, like any professional, are subjected to pressures and overloads typical of academic work. Burnout Syndrome is common in medical practice, with an incidence ranging from 25 to $60 \%$, [8] Thomas, in a representative sample of nearly 6,000 primary care physicians in a randomized study, showed that female physicians They were $60 \%$ more likely than men to show signs or symptoms of wear and tear, compared with the study that was carried out, it is similar since the prevalence obtained was $30.8 \%$, also that the frequency in the female gender 
was higher by $64 \%$ probability. Jennifer Vilchez et al. Conducted a study in which it was found that $50.6 \%$ were male, $16.5 \%, 47.7 \%$ and $35.3 \%$ of the students indicated having emotional exhaustion, severe depersonalization and low personal fulfillment, respectively, [9] differing from the one presented today in that the three aspects are at a severe level. Mayron D Nakandakari, in his study on SB, surveyed 158 human medicine students from 9 Peruvian scientific societies. $24.1 \%$ had a severe level of emotional exhaustion, $45.6 \%$ a severe level of depersonalization, $25.3 \%$ a low level of personal fulfillment and 57.6\% had BS.

$60.8 \%$ of the students were doing some research work and $49.4 \%$ held a position in their scientific society [10], similar to the study carried out, in which the aspects of emotional fatigue are at a high level $41 \%$, depersonalization at a high level in $29 \%$ and personal fulfillment the same at a high level with $45 \%$. In this order Andrea Monserrat and collaborators in their study [11] found that twenty-one $(12.3 \%)$ students had symptoms of severity at the beginning of the term, and 34 (19.8\%) after the first month ( $p=$ 0.059 ). After eliminating personal fulfillment, 54 (31.6\%) and 76 $(44.2 \%)$ students presented severity in the rest of the dimensions ( $p=0.016)$, respectively, which contrasts with the study carried out in which the group of interns corresponding to semesters XI and XII presented 58\% severe levels for emotional fatigue, 32\% high levels for depersonalization and for personal fulfillment $41 \%$ of low levels, the above allows to conclude that medical students are at risk of suffering from Syndrome Burnout for the demand and pressure to those who are exposed in the development of the race.

\section{References}

1. Luna L, Mayorga A, Taype A (2015) Burnout syndrome in undergraduate students of Human Medicine: a problem scarcely studied in Peru. An Fac Med 76(1): 83-84.

\section{ISSN: 2574-1241}

DOI: $10.26717 /$ BJSTR.2021.36.005859

Ingrid González Arteta. Biomed J Sci \& Tech Res

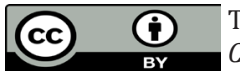

This work is licensed under Creative Commons Attribution 4.0 License

Submission Link: https://biomedres.us/submit-manuscript.php
2. Rosales RY (2012) One dimensional study of burnout syndrome in medicine students in Holguín. One-dimensional study of burnout syndrome in medicine students in Holguín. RevAsocEsp Neuropsiq 32(116): 795-803.

3. Serrano Felipe T (2016) Burnout syndrome in students from six medical schools in Colombia. 2016 -1. Multicenter Study. Cimel 21(2): 29-34.

4. Nakandakari Mayron D (2015) Burnout syndrome in medical students belonging to Peruvian scientific societies, a multicenter study. Neuropsychiatrist Journal 78(4): 203-210.

5. Martos Africa, Perwz F Maria del C, Molero Maria del M, Gazquez Jose I, Simon Maria del M (2018) European Journal of Investigation in Health. Psychology and Education 8(1): 23-36.

6. Núñez Joseli L, Bedriñana I, Mendoza Llamoca C, Zelada L (2017) Prevalence of Burnout syndrome in human medicine students from a public university in Ica, Peru 2016. Rev Med panacea 6(2): 60-63.

7. Hederich Martínez C, Caballero Domínguez C (2016) Validation of the Maslach Burnout Inventory-Student Survey (MBI-SS) questionnaire in a Colombian academic context. CES Psychology Magazine 9(1): 1-15.

8. Carrillo ER, Gómez HK, Espinoza de los Monteros EI (2012) Burnout syndrome in medical practice. Review article. Med Int Mex 28(6): 579584.

9. Vilchez Cornejo J, Huamán Gutiérrez R, Arce Villalobos L, Morán Mariños C, Mihashiro Maguiña K, et al. (2016) Burnout syndrome in medical students: frequency, characteristics and associated factors. Acta Med Peru 33(4): 282-288.

10. Mayron D, Nakandakari (2015) Burnout syndrome in medical students belonging to Peruvian scientific societies: A multicenter study. Rev Neuropsiquiatr 78(4): 2003-2010.

11. Guillén Graf AM (2018) Increase in burnout syndrome in medical students after their first month of clinical rotation. Educ Med.

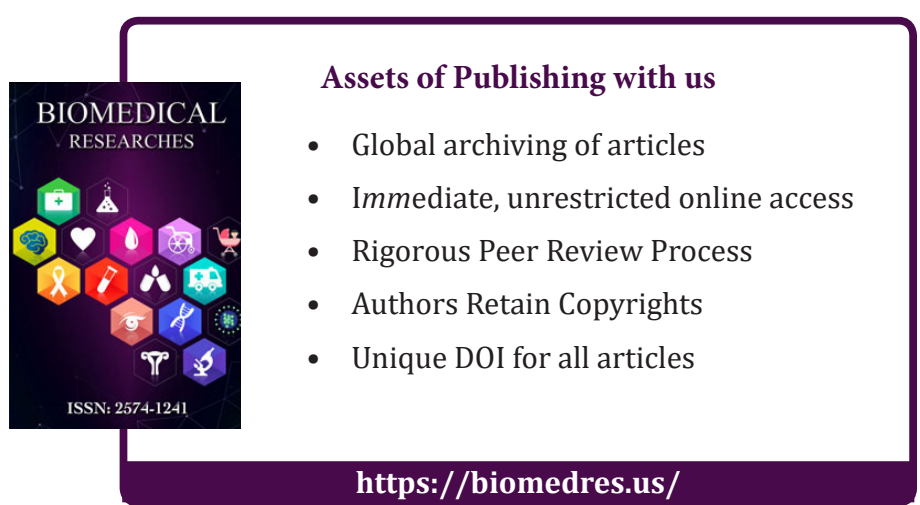

